\title{
The Timed Inspiratory Effort: A Promising Index of Mechanical Ventilation Weaning for Patients With Neurologic or Neuromuscular Diseases
}

\author{
Leonardo Cordeiro de Souza PhD PT, Fernando Silva Guimarães PhD PT, \\ and Jocemir Ronaldo Lugon PhD MD
}

\begin{abstract}
BACKGROUND: The aim of this study was to evaluate the performance of the recently described timed inspiratory effort (TIE) index in comparison with 4 other previously reported indices as to the weaning outcome in patients with neurologic or neuromuscular disorders. METHODS: This observational prospective study included subjects undergoing weaning from mechanical ventilation. The performance of the indices was evaluated by calculation of the area under the receiver operating characteristic curves. The areas under the curve were compared using the Hanley and McNeil method. $P$ values $<.05$ were considered significant. RESULTS: Seventy-two subjects $(57 \pm 20$ y old $)$ were selected for the study. Forty-three subjects were weaned, and 21 died during the study period. The mean duration of mechanical ventilation was $22.3 \pm 19.4 \mathrm{~d}$. The areas under the curve of 5 weaning predictors (TIE index, integrative weaning index, noninvasive tension-time index, maximum inspiratory pressure, and breathing frequency/tidal volume index) were significantly higher than those of the other indices. The TIE index had the largest area under the curve $(0.96 \pm 0.02)$ in comparison with the integrative weaning index $(0.82 \pm 0.05, P=.009)$, noninvasive tension-time index $(0.80 \pm 0.05, P=.001)$, maximum inspiratory pressure $(0.77 \pm 0.06, P=.001)$, and breathing frequency/tidal volume index $(0.72 \pm 0.06, P=.001)$. CONCLUSIONS: In patients with neurologic or neuromuscular impairment, the TIE index had a better performance than the best weaning indices used in clinical practice. Key words: mechanical ventilation; weaning; maximum inspiratory pressure; respiratory muscle; critical care. [Respir Care 2015;60(2):231-238. (C) 2015 Daedalus Enterprises]
\end{abstract}

\section{Introduction}

Previous studies have reported that ventilator weaning and extubation failures in subjects with neurologic and neuro-

\footnotetext{
Dr de Souza is affiliated with the Medical Science Post-graduation Program, and Dr Lugon is affiliated with the Nephrology Division, Department of Medicine, Fluminense Federal University, Niterói, Rio de Janeiro, Brazil. Dr Guimarães is affiliated with the Physiotherapy School, Federal University of Rio de Janeiro, Rio de Janeiro, Brazil.

The authors have disclosed no conflicts of interest.

Correspondence: Leonardo Cordeiro de Souza PhD PT, Icaraí Hospital, Rua Marquês de Paraná 233, $5^{\circ}$ Andar, CEP 24030-215, Centro, Niterói, Rio de Janieiro, Brazil. E-mail: leonardo.uti@gmail.com.
}

DOI: $10.4187 /$ respcare. 03393 muscular diseases are related to severity of the injury. ${ }^{1,2}$ Moreover, lower Glasgow coma scores on admission and/or lower pulmonary capacity and inadequate toilet have been associated with increased duration of ventilation. ${ }^{1}$

Weaning decisions based solely on expert clinical judgment are not always correct. ${ }^{3}$ Previous reports suggest that clinical judgment based on traditional respiratory parameters and the level of neuromuscular impairment ${ }^{4-7}$ may prevent unnecessary delay of withdrawal from mechanical ventilation and mitigate complications such as diaphragm atrophy and weakness. ${ }^{8,9}$

A number of procedures to verify patients' readiness for weaning have been proposed..$^{10}$ Currently, the 3 weaning readiness assessments should include the following steps: measurement of weaning predictor indices, unassisted breathing trial (ie, low-pressure support or T-tube trial), and extubation trial. ${ }^{11}$ 
Spontaneous ventilation is dependent on the drive from the central nervous system, the capacity of the respiratory muscles, and the load imposed on them. Factors most likely to be predictive of extubation outcome are those assessing the effectiveness of breathing efforts and/or the load of the respiratory muscles. ${ }^{12}$ In fact, univariate indices that examine a single aspect of physiologic function often have poor predictive power probably because they do not fully reflect all the pathophysiologic processes affecting weaning outcome. ${ }^{13-15}$ Accordingly, predictions that use multivariate indices that integrate a number of physiologic functions are more accurate. ${ }^{13-17}$

On reviewing the literature for ventilator weaning, 5 indices demonstrated enough accuracy for predicting the weaning outcome: frequency/tidal volume $\left(\mathrm{f} / \mathrm{V}_{\mathrm{T}}\right),{ }^{10,13} \max$ imum inspiratory pressure with unidirectional valve $\left(\mathrm{P}_{\mathrm{Imax}(\mathrm{UV})}\right),{ }^{10,13,16,18,19}$ integrative weaning index (IWI), ${ }^{16}$ tension-time index of inspiratory muscles $\left(\mathrm{TT}_{\mathrm{mus}}\right),{ }^{14,17}$ and timed inspiratory effort (TIE). ${ }^{19}$

Unfortunately, conventional weaning predictive indices have less accuracy in patients with neurologic or neuromuscular diseases. ${ }^{20}$ We hypothesized that the recently reported TIE index, which combines the ability to generate an inspiratory pressure with the time needed to achieve $\mathrm{P}_{\text {Imax }}$, could perform better in such a group of patients. Thus, the objective of this study was to compare the predictive performance of the TIE index with the 4 best previously described weaning indices in patients with neurologic or neuromuscular diseases.

\section{Methods}

\section{Subjects and Settings}

This study was conducted in the ICU of a general hospital. The ICU is a closed 33-bed unit attended by 4 physicians certified and trained in critical care, two 24-h respiratory physiotherapists, 2 senior nurses, and nurse assistants (at a ratio of one for 3 patients).

The study was approved by the ethics committee of the Fluminense Federal University (number 259/09). Informed consent was obtained from each subject, whenever possible, or from the subject's next-of-kin. We utilized the same database used in a previous report, ${ }^{19}$ complementing the analysis focusing on subjects with neurologic or neuromuscular diseases.

All mechanically ventilated subjects who were clinically stable and judged ready to undergo a weaning trial by their primary physicians and respiratory physiotherapists were enrolled in this prospective observational study. Inclusion criteria included: 18 y or older, a neurologic or neurosurgical condition, and mechanical ventilation for $>24 \mathrm{~h}$. Subjects were accepted for enrollment if they met the American Thoracic Society/European Respiratory So-

\section{QUICK LOOK}

\section{Current knowledge}

Weaning and extubation failures in patients with neurologic and neuromuscular disorders are associated with increased disease severity. The timed inspiratory effort (TIE) index combines the ability to generate an inspiratory pressure with the time needed to achieve the maximum inspiratory pressure $\left(\mathrm{P}_{\text {Imax }}\right)$. The role of the TIE index in predicting weaning success in neurologic and neuromuscular disease has not been studied.

\section{What this paper contributes to our knowledge}

In a small group of subjects with neurologic disease or neuromuscular impairment, TIE was superior to the breathing frequency/tidal volume ratio, $\mathrm{P}_{\text {Imax }}$, and integrative weaning index in predicting weaning success. Large trials are required before adoption of this predictive index.

ciety 2007 guidelines to start a weaning trial. ${ }^{10}$ These criteria were as follows: resolution of the acute phase of the disease for which the subject was intubated, adequate cough reflex or absence of excessive tracheobronchial secretions, stable cardiovascular status (heart rate of $\leq 120$ beats $/ \mathrm{min}$ and systolic arterial blood pressure of $90-160 \mathrm{~mm} \mathrm{Hg}$, with no or minimal use of vasopressors), stable metabolic status, adequate oxygenation (arterial oxygen saturation $\left[\mathrm{S}_{\mathrm{aO}_{2}}\right]$ of $>90 \%$ on $\mathrm{F}_{\mathrm{IO}_{2}} \leq 0.4$ or $\mathrm{P}_{\mathrm{aO}_{2}} / \mathrm{F}_{\mathrm{IO}_{2}} \geq 200 \mathrm{~mm} \mathrm{Hg}$ with PEEP $\leq 8 \mathrm{~cm} \mathrm{H} \mathrm{H}_{2} \mathrm{O}$ ), adequate ventilatory pattern (breathing frequency of $\leq 35$ breaths/min) with pressure support of $\leq 16 \mathrm{~cm} \mathrm{H}_{2} \mathrm{O}$, no significant respiratory acidosis $(\mathrm{pH}>7.30)$, and adequate mentation or a Glasgow coma score of $>10$ (only for subjects with an endotracheal tube).

Exclusion criteria were as follows: tracheal stenosis, intracranial pressure of $>20 \mathrm{~mm} \mathrm{Hg}$, sedation, overt cardiac failure or hemodynamic instability, and signs of systemic infection/re-infection during the weaning process. The Taema eXtend ventilator (Air Liquide, Gentilly, France) was used.

\section{Study Procedures}

Discontinuation from mechanical ventilation was attempted when the physician in charge judged that the subject was ready to be weaned according to the aforementioned criteria. Before testing, all subjects were under pressure support ventilation (ranging from 5 to $16 \mathrm{~cm} \mathrm{H}_{2} \mathrm{O}$ ), with PEEP varying from 5 to $8 \mathrm{~cm} \mathrm{H}_{2} \mathrm{O}$. The subjects were 


\section{Timed InSPIRATORY EFFORT AS AN INDEX OF WEANING}

not sedated (they were all between +1 and -1 on the Richmond Agitation-Sedation Scale ${ }^{21}$ ) and were allowed to breathe spontaneously for $10 \mathrm{~s}$ before performing the test. ${ }^{22-23}$ They were in a semirecumbent position $\left(45^{\circ}\right)$, with their airways suctioned, and were pre-oxygenated for 2 min with an $\mathrm{F}_{\mathrm{IO}_{2}}$ of 1.0.22-23 The endotracheal tube cuff was hyperinflated to prevent air leakage during measurements. ${ }^{22-23}$

First, the variables that could be registered under mechanical ventilation were obtained. Second, spirometry was performed, and the subject was returned to mechanical ventilation. After stabilization, subjects were connected to a vacuometer and a unidirectional valve. After measurements of all indices, subjects were to left to recover for 5-10 min and underwent a 30-min spontaneous breathing trial with a T-piece at a $\mathrm{F}_{\mathrm{IO}_{2}}$ of 0.4. All subjects were continuously monitored by pulse oximetry and electrocardiography, with continuous respiratory physiotherapist attention. The following 5 weaning indices were evaluated: $\mathrm{P}_{\mathrm{Imax}(\mathrm{UV})}, \mathrm{f} / \mathrm{V}_{\mathrm{T}}, \mathrm{IWI}, \mathrm{TT}_{\mathrm{mus}}$, and TIE.

The $f / \mathrm{V}_{\mathrm{T}}$ index was measured with a bedside spirometer (Wright MK-20, Ferraris Medical, Hertford, United Kingdom) attached to an artificial airway for $1 \mathrm{~min}$. The spontaneous $\mathrm{V}_{\mathrm{T}}$ was calculated by dividing the minute ventilation by the breathing frequency, and $f / V_{T}$ was calculated by dividing the breathing frequency by $\mathrm{V}_{\mathrm{T}}$ (average of $60 \mathrm{~s}$, in L). ${ }^{13}$

The IWI uses the static compliance of the respiratory system $\left(\mathrm{C}_{\mathrm{RS}}\right), \mathrm{S}_{\mathrm{aO}_{2}}$, and $\mathrm{f} / \mathrm{V}_{\mathrm{T}}$ : IWI $=$ static $\mathrm{C}_{\mathrm{RS}} \times \mathrm{S}_{\mathrm{aO}_{2}} /\left(\mathrm{f} / \mathrm{V}_{\mathrm{T}}\right)$. The static $\mathrm{C}_{\mathrm{RS}}$ was calculated as described by Aboussouan et $\mathrm{al}^{24}$ using the volume and pressure readout on the ventilator display. An inspiratory hold of $2 \mathrm{~s}$ was used to record the plateau pressure $\left(\mathrm{P}_{\text {plat }}\right.$ ), and the static $\mathrm{C}_{\mathrm{RS}}$ was calculated by dividing the $\mathrm{V}_{\mathrm{T}}$ by the difference between the inspiratory $\mathrm{P}_{\text {plat }}$ and PEEP: static $\left.\mathrm{C}_{\mathrm{RS}}=\mathrm{V}_{\mathrm{T}} / \mathrm{P}_{\text {plat }}-\mathrm{PEEP}\right){ }^{16,19}$

$\mathrm{TT}_{\text {mus }}$ is obtained noninvasively and assesses the inspiratory muscle function by the following equation: $\mathrm{TT}_{\text {mus }}=$ $\left(\mathrm{P}_{\mathrm{I}} / \mathrm{P}_{\mathrm{Imax}(\mathrm{UV})}\right) \times\left(\mathrm{T}_{\mathrm{I}} / \mathrm{T}_{\text {tot }}\right)$, where $\mathrm{P}_{\mathrm{I}}$ is inspiratory pressure estimated as $5 \times \mathrm{P}_{0.1} \times \mathrm{T}_{\mathrm{I}}, 25,26 \mathrm{~T}_{\mathrm{I}}$ is inspiratory time, and $\mathrm{T}_{\text {tot }}$ is the total respiratory cycle time obtained from the mechanical ventilation parameters during the testing period. . $^{14,17,25,26}$

The TIE index was recorded using the unidirectional valve method and calculated as the ratio between $\mathrm{P}_{\mathrm{Imax}(\mathrm{UV})}$ and the corresponding time to achieve it in $60 \mathrm{~s}$ of observation. ${ }^{19} \mathrm{P}_{\mathrm{Imax}(\mathrm{UV})}$ and respiratory drive $\left(\mathrm{P}_{0.1}\right)$ were obtained using a digital vacuometer (MVD 300, GlobalMed, Porto Alegre, Rio Grande do Sul, Brazil). This device has a range of $300 \mathrm{~cm} \mathrm{H}_{2} \mathrm{O}$ with a $1 \mathrm{~cm} \mathrm{H}_{2} \mathrm{O}$ interval and is designed to perform measurements every $100 \mathrm{~ms}$. Measurements were digitally recorded, allowing easy access to the parameter values whenever needed. ${ }^{18,19,23}$ For this study, $\mathrm{P}_{\text {Imax(UV) }}$ was taken as the peak value in the first $20 \mathrm{~s}$ of observation, and $\mathrm{P}_{0.1}$ as the mean of the first 3 respiratory cycles. ${ }^{18,19,23}$ Subjects were not coached for the maneuver. ${ }^{18,19,22,23}$

The decision to return to mechanical ventilation was made by a respiratory physiotherapist and the physician in charge (both were blinded to the results of the indices evaluated) based on the signs of poor tolerance described below. $8,10,16,27,28$ Weaning was considered successful if spontaneous breathing was sustained for $>48 \mathrm{~h}$ after withdrawal from mechanical ventilation (through the tracheostomy tube for tracheostomized subjects and after extubation for those who were orally intubated). ${ }^{10,16,19,23,27,28}$

The trial was stopped if at least one of the following intolerance criteria was present: $\mathrm{S}_{\mathrm{aO}_{2}}<90 \%$ or $\mathrm{P}_{\mathrm{aO}_{2}}<$ $60 \mathrm{~mm} \mathrm{Hg}$ with $\mathrm{F}_{\mathrm{IO}_{2}}>0.4 ; \mathrm{P}_{\mathrm{aCO}_{2}}>50 \mathrm{~mm} \mathrm{Hg}$ or increased by $\geq 8 \mathrm{~mm} \mathrm{Hg}$; arterial $\mathrm{pH}<7.33$ or decreased by 0.07 or more; breathing frequency $>35$ breaths/min or increased by $50 \%$ for 5 min or longer; heart rate $>140$ beats/ min or a sustained increase or decrease of $>20 \%$; mean blood pressure $>130$ or $<70 \mathrm{~mm} \mathrm{Hg}$; or presence of agitation, diaphoresis, disorientation, or depressed mental status. ${ }^{10,16,19,23,27-29}$ Subjects who demonstrated one of these signs during the spontaneous breathing trial or within $48 \mathrm{~h}$ after discontinuation from mechanical ventilation were considered to have failed weaning and were returned to ventilatory support. ${ }^{8,10,16,27,29}$ Any death occurring within $48 \mathrm{~h}$ of weaning was also computed as a failure.

\section{Statistical Analysis}

Continuous variables are expressed as mean $\pm \mathrm{SD}$, and categorical variables as frequencies. Comparisons between groups were performed by the Mann-Whitney test or chisquare test as appropriate. The end point of the study was successful weaning. The performance of the indices to predict weaning outcome was evaluated by calculation of sensitivity, specificity, predictive values, and likelihood ratios. The areas under the receiver operating characteristic (ROC) curves, which are built integrating sensitivity and specificity, were also obtained; thresholds for the 5 weaning indices were calculated using the Youden method. ${ }^{30}$ Areas under the curves were compared using the method of Hanley and McNeil. ${ }^{30} P<.05$ was considered significant.

Statistical analysis was performed employing SPSS 18.0 (SPSS, Chicago, Illinois). Comparison between ROC curves was accomplished using MedCalc 11.4.2.0. (Mariakerke Software, Mariakerke, Belgium).

\section{Results}

From the 990 patients admitted to the ICU of the hospital between July 2011 and July 2012, 67 were eligible for the study (Fig. 1). Subjects who were successfully 


\section{Timed InSPIRATORY EFFORT AS AN INDEX OF WEANING}

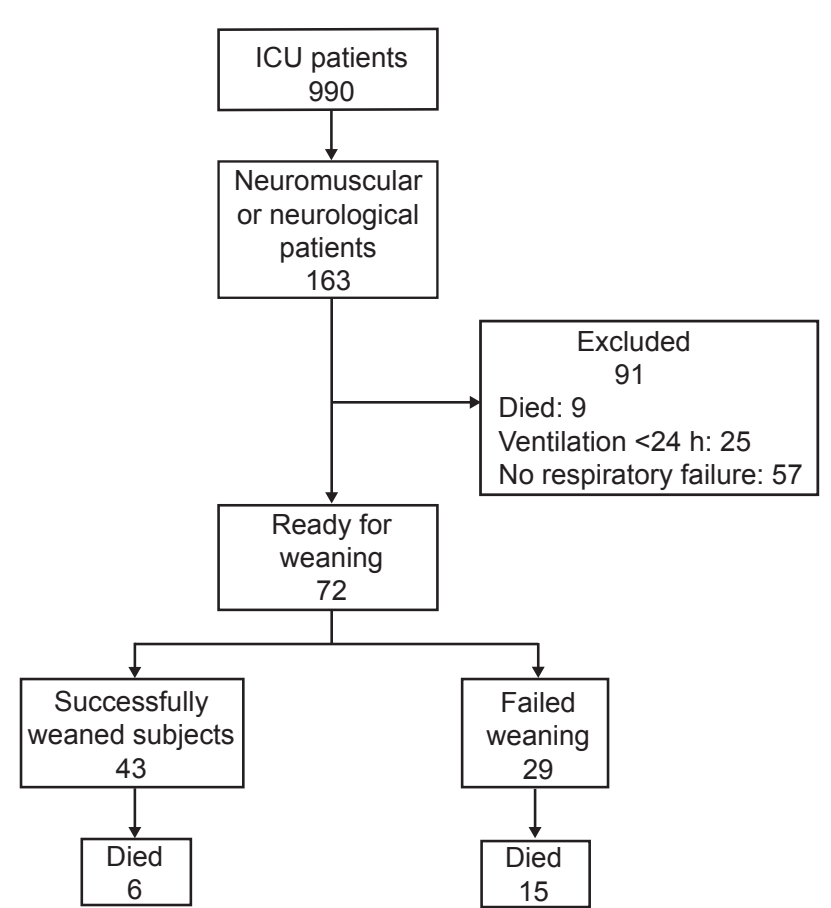

Fig. 1. Flow of subjects in the study indicating stratification of the groups according to weaning outcome and exclusions.

weaned were in group 1 , and those who failed the weaning trial were in group 2.

All subjects in groups 1 and 2 used orotracheal or tracheostomy tubes with internal diameters of 7.5-9.0 mm. Twenty-one subjects (31\%) died before discharge, including 6 among the successfully weaned subjects.

The subjects' characteristics and the differences between the groups are provided in Table 1 . The conditions precipitating ICU admissions were brain trauma (22 cases, $68 \%$ subjects with tracheostomies), stroke (27 cases, 66\% subjects with tracheostomies), acute myopathy (19 cases, $89 \%$ subjects with tracheostomies), and cervical medullary injury (4 cases, $100 \%$ subjects with tracheostomies). Of the subjects with stroke, 23 had cerebral ischemia, 2 had intracerebral hemorrhage, and 2 had subarachnoid hemorrhage. Of the acute myopathy subjects, 6 had critical illness polyneuropathy, 3 had Guillain-Barré syndrome, 2 had polymyositis, one had cerebral palsy (as a sequel of meningitis), one had porphyria, one had inclusion body myositis, one had Parkinson disease, and 2 had myasthenia gravis.

Among the monitored parameters during the test, an increase in breathing frequency was the most common reason for returning subjects to mechanical ventilation. The mean values of the measured parameters used to calculate the weaning predictor indices as well as the indices themselves in both groups are provided in Table 2. Quality indicators and the cutoff values calculated from the ROC curves of the 5 weaning indices (TIE, IWI, TT ${ }_{\text {mus }}$,
$\left.\mathrm{P}_{\mathrm{Imax}(\mathrm{UV})}\right)$, and $\mathrm{f} / \mathrm{V}_{\mathrm{T}}$ ) are provided in Table 3. The IWI exhibited a slightly higher sensitivity than the remaining ones, but the TIE index showed a better performance in every other quality indicator. The area under the curve of the 5 indices and the statistics between them are provided in Figure 2. The largest area under the curve was found for the TIE index $(0.96 \pm 0.02)$, followed by IWI $(0.82 \pm 0.05)$, $\mathrm{TT}_{\text {mus }}(0.80 \pm 0.05), \mathrm{P}_{\mathrm{Imax}(\mathrm{UV})}(0.77 \pm 0.06, P=.001)$, and $\mathrm{f} / \mathrm{V}_{\mathrm{T}}(0.72 \pm 0.06)$. The values for the TIE index were statistically higher than those for every other index. A post hoc analysis was performed to calculate the area under the ROC curve for each index, separating subjects who had tracheostomies (Table 4). Again, the highest areas under the curve were found for the TIE index, irrespective of the presence of a tracheostomy.

\section{Discussion}

The use of predictive weaning indices is one of the most studied phenomena in intensive care. ${ }^{11}$ However, their performance in patients with neuromuscular diseases has been found to be poor. ${ }^{12,16,19}$ In this study, we evaluated the performance of 5 selected weaning indices in subjects with critical neurologic or neuromuscular diseases. In our sample, the weaning failure rate (39\%) was greater than that in the literature, which is $\sim 30 \% .^{10}$ This finding was not unexpected considering that we dealt with subjects with neurologic or neuromuscular diseases, who are more likely to have complications. Accordingly, our subjects had a prolonged duration of mechanical ventilation ( $22 \mathrm{~d})$, a high tracheotomy rate (75\%), a high death rate in the ICU (31\%), and a high APACHE II score (17.9). Subjects who failed the weaning trial had longer ventilation times, higher tracheotomy rates, greater ICU mortality, and less brain trauma.

The mean of every tested respiratory parameter was statistically different between successful and failed weaning subjects (see Table 2). Cutoff points of the weaning indices provided in Table 3 were obtained by ROC curve analysis using the Youden index. The TIE index and $\mathrm{P}_{\mathrm{Imax}(\mathrm{UV})}$ maintained the previously published cutoff values of 1 and 30, ${ }^{19}$ whereas the other weaning indices did not. ${ }^{13,16,17}$

The previously mentioned specificities of the study group may in part account for these differences. Numbers regarding sensitivity, negative predictive values, and likelihood ratios of negative tests were comparable among the various weaning indices. In contrast, specificity, positive predicted values, and likelihood ratios of positive tests were markedly superior for the TIE index compared with the other weaning tests.

To better explore the relative performance of the weaning tests, ROC curves for each tested index were generated (see Fig. 2). The area under the curve of the TIE index was 
Table 1. General Characteristics of Subjects

\begin{tabular}{|c|c|c|c|c|}
\hline & \multirow{2}{*}{ All Subjects } & \multicolumn{2}{|c|}{ Weaning } & \multirow{2}{*}{$P$} \\
\hline & & Success & Failure & \\
\hline Subjects, $n(\%)$ & 72 & $43(60)$ & $29(40)$ & Group 2 vs group 1 \\
\hline Males/females, $n$ & $48 / 24$ & $30 / 13$ & $18 / 11$ & .43 \\
\hline Blacks/whites, $n$ & $47 / 25$ & $31 / 12$ & $16 / 13$ & .10 \\
\hline Age (mean $\pm S D), y$ & $57.3 \pm 20$ & $56.7 \pm 18.9$ & $58.3 \pm 22.4$ & .39 \\
\hline Mechanical ventilation (mean $\pm S D$ ), $d^{*}$ & $22.3 \pm 19.4$ & $19.9 \pm 20.6$ & $26.5 \pm 17.1$ & .02 \\
\hline OTT/Trach, $n$ & $18 / 54$ & $15 / 28$ & $3 / 26$ & .04 \\
\hline Death in ICU, $n(\%)$ & $21(31)$ & $6(9)$ & $15(22)$ & .08 \\
\hline APACHE II score (mean \pm SD) & $17.9 \pm 6.4$ & $17.1 \pm 5.5$ & $19.3 \pm 7.5$ & .21 \\
\hline \multicolumn{5}{|c|}{ Conditions precipitating ICU admission, $n$ (\%) } \\
\hline Brain trauma & $22(31)$ & $17(39)$ & $5(17)$ & .02 \\
\hline Stroke & $27(39)$ & $17(40)$ & $10(35)$ & .25 \\
\hline Acute myopathy & $19(25)$ & $7(16)$ & $12(41)$ & .36 \\
\hline Cervical medullary injury & $4(5)$ & $2(5)$ & $2(7)$ & .62 \\
\hline \multicolumn{5}{|c|}{$\begin{array}{l}\text { * Until the first weaning trial } \\
\text { OTT }=\text { Subjects with } \leq 14 \mathrm{~d} \text { of mechanical ventilation and orotracheal tube } \\
\text { Trach = Subjects with }>14 \text { days of mechanical ventilation and tracheostomized } \\
\text { APACHE II = Acute Physiology and Chronic Health Evaluation II }\end{array}$} \\
\hline
\end{tabular}

Table 2. Respiratory Parameters According to Weaning Outcome

\begin{tabular}{lccc}
\hline \hline Parameter & $\begin{array}{c}\text { Success, } \\
\text { Mean } \pm \mathrm{SD} \\
(n=43)\end{array}$ & $\begin{array}{c}\text { Failure, } \\
\text { Mean } \pm \mathrm{SD} \\
(n=29)\end{array}$ & $P^{*}$ \\
\hline $\mathrm{P}_{0.1}$ & $3.02 \pm 0.94$ & $2.60 \pm 0.69$ & .03 \\
$\mathrm{P}_{\text {Imax(UV) }}$ & $39.26 \pm 21.45$ & $22.93 \pm 11.28$ & $<.001$ \\
$\mathrm{TIE}$ index & $1.55 \pm 0.80$ & $0.70 \pm 0.20$ & $<.001$ \\
$\mathrm{f} / \mathrm{V}_{\mathrm{T}}$ & $75.32 \pm 29.44$ & $94.00 \pm 22.97$ & $<.001$ \\
$\mathrm{IWI}$ & $59.34 \pm 22.08$ & $37.23 \pm 18.51$ & $<.001$ \\
$\mathrm{TT}_{\operatorname{mus}}$ & $0.18 \pm 0.09$ & $0.39 \pm 0.22$ & $<.001$ \\
$\mathrm{~T}_{\mathrm{I}} / \mathrm{T}_{\text {tot }}$ & $0.43 \pm 0.17$ & $0.55 \pm 0.18$ & $<.001$ \\
$\mathrm{P}_{\mathrm{I}}$ & $14.33 \pm 5.30$ & $13.84 \pm 4.16$ & .82 \\
$\mathrm{P}_{\mathrm{I}} / \mathrm{P}_{\text {Imax(UV) }}$ & $0.41 \pm 0.10$ & $0.69 \pm 0.29$ & $<.001$ \\
$\mathrm{~T}_{\mathrm{I}}$ & $0.95 \pm 0.16$ & $1.07 \pm 0.21$ & .01 \\
$\mathrm{f}$ & $26.40 \pm 4.71$ & $30 \pm 5.83$ & $<.001$ \\
$\mathrm{~V}_{\mathrm{T}}$ & $0.36 \pm 0.07$ & $0.33 \pm 0.07$ & .03 \\
& & &
\end{tabular}

* Nonparametric Mann-Whitney test

$\mathrm{P}_{0.1}=$ respiratory drive

$\mathrm{P}_{\operatorname{Imax}(\mathrm{UV})}=$ maximum inspiratory pressure with unidirectional valve

$\mathrm{TIE}=$ timed inspiratory effort

$\mathrm{f} / \mathrm{V}_{\mathrm{T}}$ ratio $=$ breathing frequency/tidal volume ratio

IWI = integrative weaning index

$\mathrm{TT}_{\mathrm{mus}}=$ tension-time index of inspiratory muscles

$\mathrm{T}_{\mathrm{I}} / \mathrm{T}_{\text {tot }}=$ inspiratory time/total cycle time ratio

$\mathrm{P}_{\mathrm{I}}=$ inspiratory pressure

significantly higher than those of the other tested weaning indices. The finding was confirmed when subjects with or without a tracheostomy were analyzed separately.

Historically, the consensus of the American Thoracic Society/European Respiratory Society is that the indices $\mathrm{f} / \mathrm{V}_{\mathrm{T}}$ and $\mathrm{P}_{\text {Imax }}$ are the most frequently used to indicate if patients are ready to undergo a weaning process. ${ }^{10}$ Recent studies have shed light on the clinical utility of new weaning indices: the $\mathrm{TT}_{\text {mus }}$ exhibited a surprisingly performance with an area under the curve of 1.0 in children with neurologic disorders ${ }^{17}$; the IWI showed an area under the curve of 0.96 in adult patients without neurologic diseases $^{16}$; and the TIE index revealed an area under the curve of 0.90 in a general population of adults in the ICU. The results of the last 3 indices are superior to the better results reported for $\mathrm{f} / \mathrm{V}_{\mathrm{T}}$ (area under the curve $=0.89$ ) and $\mathrm{P}_{\mathrm{Imax}(\mathrm{UV})}$ (area under the curve $=0.80$ ) in this setting. ${ }^{13,19}$ In our study, the TIE index was found to have the best performance in predicting weaning outcome.

The TIE index critically evaluates how fast a patient can generate $\mathrm{P}_{\text {Imax }}$, which is dependent on central stimuli and muscle power. ${ }^{19}$ Our hypothesis was that TIE index reflects neuromuscular performance and can be particularly useful in identifying ready-to-wean patients in the class of subjects in our study. Our results allow us to suggest the TIE index as an eligible predictor of weaning in those patients for whom the performance of other indices such as $f / V_{T}$ and $P_{0.1}$ is recognized to be poor. ${ }^{20,27,31}$ Indeed, the well-known low accuracy of other indices was perhaps the reason why this class of patients was used as an exclusion criterion in a previous study. ${ }^{16}$

Because this is the first investigation on the reliability of the TIE index for subjects with neurologic or neuromuscular diseases, the external validity of these results is limited by the small sample size. Therefore, the clinical application of our findings should await further studies with larger samples. It should also be noted that our study population represents a heterogeneous collection comprising 


\section{TIMED INSPIRATORY EFFORT AS AN INDEX OF WEANING}

Table 3. Quality Indicators of Indexes Used to Predict Weaning Outcome

\begin{tabular}{|c|c|c|c|c|c|c|c|}
\hline Index & Cutoff & Sensitivity & Specificity & $\begin{array}{c}\text { Positive } \\
\text { Predictive Value }\end{array}$ & $\begin{array}{c}\text { Negative } \\
\text { Predictive Value }\end{array}$ & $\begin{array}{c}\text { Positive } \\
\text { Likelihood Ratio }\end{array}$ & $\begin{array}{c}\text { Negative } \\
\text { Likelihood Ratio }\end{array}$ \\
\hline TIE & $>1.00$ & 0.86 & 0.96 & 97.3 & 80.6 & 22.4 & 0.14 \\
\hline IWI & $>37$ & 0.90 & 0.69 & 83.7 & 79.2 & 3.26 & 0.17 \\
\hline $\mathrm{TT}_{\text {mus }}$ & $\leq 0.27$ & 0.83 & 0.73 & 82.9 & 73.1 & 3.08 & 0.23 \\
\hline $\mathrm{f} / \mathrm{V}_{\mathrm{T}}$ & $\leq 93$ & 0.85 & 0.61 & 77.8 & 72.7 & 2.22 & 0.24 \\
\hline $\mathrm{P}_{\operatorname{Imax}(\mathrm{UV})}$ & $>30$ & 0.60 & 0.82 & 0.84 & 0.62 & 3.51 & 0.48 \\
\hline $\begin{array}{l}\text { Cutoff values } \\
\mathrm{TIE}=\text { timed } \\
\mathrm{IWI}=\text { integra } \\
\mathrm{TT}_{\text {mus }}=\text { tensi } \\
\mathrm{f} \mathrm{V}_{\mathrm{T}}=\text { freque } \\
\mathrm{P}_{\mathrm{Imax}(\mathrm{UV})}=\mathrm{m}\end{array}$ & $\begin{array}{l}\text { sponds to the } \\
\text { atory effort } \\
\text { veaning index } \\
\text { ne index of i } \\
\text { dal volume } r \\
\text { um inspirator }\end{array}$ & $\begin{array}{l}\text { ory muscles } \\
\text { sure with unidir }\end{array}$ & & & & & \\
\hline
\end{tabular}
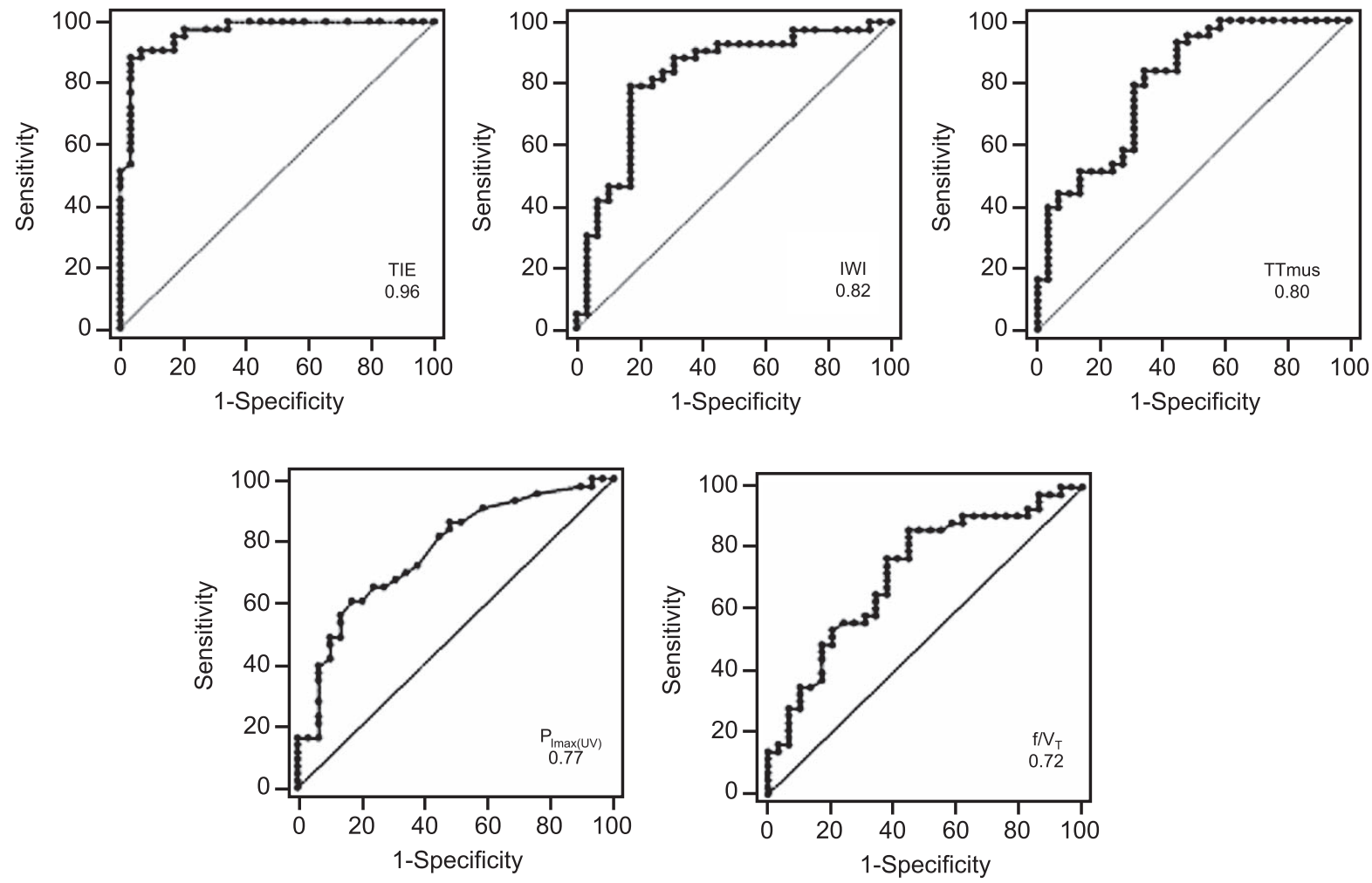

\begin{tabular}{lcccc|}
\hline & $\mathrm{f} / \mathrm{V}_{\mathrm{T}}$ & $\mathrm{P}_{\operatorname{Imax}(\mathrm{UV})}$ & TTmus & IWI \\
\hline TIE & .0001 & .0001 & .001 & .009 \\
$\mathrm{IWI}$ & .02 & .78 & .75 & \\
TTmus & .26 & .54 & & \\
$\mathrm{P}_{\text {Imax(UV) }}$ & .57 & & & \\
\hline
\end{tabular}

Fig. 2. Area under the receiver operating characteristic curves of the 4 predictors of successful weaning in this study: timed inspiratory effort $(\mathrm{TIE})$, integrative weaning index (IWI), tension-time index of inspiratory muscles $\left(\mathrm{TT}_{\text {mus }}\right)$, maximum inspiratory pressure with unidirectional valve $\left(\mathrm{P}_{\mathrm{Imax}(\mathrm{UV})}\right)$, and frequency/tidal volume ratio $\left(\mathrm{f} / \mathrm{V}_{\mathrm{T}}\right) . P$ values for each comparison are provided. 


\section{Timed Inspiratory EFFort as AN INDEX OF WeANing}

Table 4. Performance of Weaning Indexes as Evaluated by Areas Under the Receiver Operating Characteristic Curves in Subjects With Orotracheal Tubes or Tracheostomies

\begin{tabular}{lcc}
\hline \hline \multicolumn{1}{c}{ Index } & $\begin{array}{c}\text { Orotracheal Tube, } \\
\text { Mean } \pm \mathrm{SD} \\
(n=18)\end{array}$ & $\begin{array}{c}\text { Tracheostomy, } \\
\text { Mean } \pm \mathrm{SD} \\
(n=54)\end{array}$ \\
\hline $\mathrm{TIE}$ & $1.00 \pm 0.09$ & $0.95 \pm 0.03$ \\
$\mathrm{TT}_{\text {mus }}$ & $0.91 \pm 0.09$ & $0.75 \pm 0.06$ \\
$\mathrm{P}_{\mathrm{Imax}(\mathrm{UV})}$ & $0.84 \pm 0.09$ & $0.75 \pm 0.06$ \\
$\mathrm{IWI}$ & $0.75 \pm 0.12$ & $0.84 \pm 0.05$ \\
$\mathrm{f} / \mathrm{V}_{\mathrm{T}}$ & $0.71 \pm 0.12$ & $0.72 \pm 0.07$
\end{tabular}

TIE $=$ timed inspiratory effort

$\mathrm{TT}_{\text {mus }}=$ tension-time index of inspiratory muscles

$\mathrm{P}_{\mathrm{Imax}(\mathrm{UV})}=$ maximum inspiratory pressure with unidirectional valve

IWI $=$ integrative weaning index

$\mathrm{f} / \mathrm{V}_{\mathrm{T}}$ ratio $=$ frequency/tidal volume ratio

brain trauma, stroke, and neuromuscular diseases. Heterogeneous sedation levels due to residual effects of drugs could have a role in this regard, but the impact was attenuated by the regular use of the Richmond Agitation-Sedation Scale. ${ }^{21}$ We think that it would be desirable to assess the performance of these indices in each one of these specific groups in the future. Despite these limitations, our results are encouraging and suggest that the TIE index can be a useful tool in the clinical management of patients whose weaning readiness is difficult to predict.

\section{Conclusions}

In summary, the TIE index was found to be useful in predicting successful weaning in subjects with critical neurologic diseases, and it performed better than the other weaning indices tested in this setting. We hope that regular utilization of this index might attenuate the burden of a wrong decision for extubation or unnecessary prolongation of mechanical ventilation in such patients.

\section{ACKNOWLEDGMENTS}

We thank the respiratory physiotherapists (especially Arthur Evangelista da Silva Neto) and physicians of the ICU of the Hospital Icaraí for their collaboration.

\section{REFERENCES}

1. Kelly BJ, Matthay MA. Prevalence and severity of neurologic dysfunction in critically ill patients. Influence on need for continued mechanical ventilation. Chest 1993;104(6):1818-1824.

2. Call MS, Kutcher ME, Izenberg RA, Singh T, Cohen MJ. Spinal cord injury: outcomes of ventilatory weaning and extubation. J Trauma 2011;71(6):1673-1679.

3. Navalesi P, Frigerio P, Moretti MP, Sommariva M, Vesconi S, Baiardi $P$. Rate of reintubation in mechanically ventilated neurosurgical and neurologic patients: evaluation of a systematic approach to weaning and extubation. Crit Care Med 2008;36(11):2986-2992.
4. Ely EW, Baker AM, Dunagan DP, Burke HL, Smith AC, Kelly PT, et al. Effect on the duration of mechanical ventilation of identifying patients capable of breathing spontaneously. N Engl J Med 1996; 335(25):1864-1869.

5. Tobin MJ. Advances in mechanical ventilation. N Engl J Med 2001; 344(26): 1986-1996.

6. Namen AM, Ely EW, Tatter SB, Case LD, Lucia MA, Smith A, et al. Predictors of successful extubation in neurosurgical patients. Am J Respir Crit Care Med 2001;163(3):658-664.

7. Lellouche F, Mancebo J, Jolliet P, Roeseler J, Schortgen F, Dojat M, et al. A multicenter randomized trial of computer-driven protocolized weaning from mechanical ventilation. Am J Respir Crit Care Med 2006;174(8):894-900

8. Epstein SK. Decision to extubate. Intensive Care Med 2002;28(5): 535-546.

9. Levine S, Nguyen T, Taylor N, Friscia ME, Budak MT, Rothenberg $\mathrm{P}$, et al. Rapid disuse atrophy of diaphragm fibers in mechanically ventilated humans. N Engl J Med 2008;358(13):1327-1335.

10. Boles JM, Bion J, Connors A, Herridge M, Marsh B, Melot C, et al. Weaning from mechanical ventilation. Eur Respir J 2007;29(5):10331056.

11. Tobin MJ. The new irrationalism in weaning. J Bras Pneumol 2011; 37(5):571-573.

12. Khan N, Brown A, Venkataraman ST. Predictors of extubation success and failure in mechanically ventilated infants and children. Crit Care Med 1996;24(9):1568-1579.

13. Yang KL, and Tobin MJ. A prospective study of indexes predicting the outcome of trials of weaning from mechanical ventilation. N Engl J Med 1991;324(21):1445-1450.

14. Ramonatxo M, Boulard P, and Préfaut C. Validation of a noninvasive tension-time index of inspiratory muscles. J Appl Physiol 1995; 78(2):646-653.

15. Tobin MJ, Jubran A. Variable performance of weaning-predictor tests: role of Bayes' theorem and spectrum and test-referral bias. Intensive Care Med 2006;32(12):2002-2012.

16. Nemer SN, Barbas CS, Caldeira JB, Cárias TC, Santos RG, Almeida $\mathrm{LC}$, et al. A new integrative weaning index of discontinuation from mechanical ventilation. Crit Care 2009;13(5):R152.

17. Harikumar G, Egberongbe Y, Nadel S, Wheatley E, Moxham J, Greenough A, Rafferty GF. Tension-time index as a predictor of extubation outcome in ventilated children. Am J Respir Crit Care Med 2009;180(10):982-988.

18. de Souza LC, da Silva CT Jr, Almeida JR, Lugon JR. Comparison of maximum inspiratory pressure, tracheal airway occlusion pressure, and its ratio in the prediction of weaning outcome: impact of the use of a digital vacuometer and the unidirectional valve. Respir Care 2012;57(8):1285-1290.

19. Souza LC, Guimarães FS, Lugon JR. Evaluation of a new index of mechanical ventilation weaning: the timed inspiratory effort. J Intensive Care Med 2013 [Epub ahead of print] doi: 10.1177/ 0885066613483265 .

20. Ko R, Ramos L, Chalela JA. Conventional weaning parameters do not predict extubation failure in neurocritical care patients. Neurocrit Care 2009;10(3):269-273.

21. Sessler CN, Gosnell MS, Grap MJ, Brophy GM, O’Neal PV, Keane KA, Tesoro EP, and Elswick RK. The Richmond Agitation-Sedation Scale: validity and reliability in adult intensive care unit patients. Am J Respir Crit Care Med 2002;166(10):1338-1344.

22. Guimarães FS, Alves FF, Constantino SS, Dias CM, and Menezes SL. Maximum inspiratory pressure evaluation among non-cooperative critical patients: comparison between two methods. Rev Bras Fisioter 2007;11(3):233-238. 


\section{TIMED INSPIRATORY EFFORT AS AN INDEX OF WEANING}

23. de Souza LC, da Silva CT Jr, Lugon JR. Evaluation of the inspiratory pressure using a digital vacuometer in mechanically ventilated patients: analysis of the time to achieve the inspiratory peak. Respir Care 2012;57(2):257-262.

24. Aboussouan LS, Lattin CD, and Anne VV. Determinants of timeto-weaning in a specialized respiratory care unit. Chest 2005;128(5): 3117-3126.

25. Mulreany LT, Weiner DJ, McDonough JM, Panitch HB, and Allen JL. Noninvasive measurement of the tension-time index in children with neuromuscular disease. J Appl Physiol 2003;95(3):931-937.

26. Hahn A, Duisberg B, Neubauer BA, Stephani U, Rideau Y. Noninvasive determination of the tension-time index in Duchenne muscular dystrophy. Am J Phys Med Rehabil 2009;88(4):322-327.

27. Nemer SN, Barbas CS, Caldeira JB, Guimarães B, Azeredo LM, Gago R, Souza PC. Evaluation of maximum inspiratory pressure, tracheal airway occlusion pressure, and its ratio in the weaning outcome. J Crit Care 2009;24(3):441-446.

28. Conti G, Montini L, Pennisi MA, Cavaliere F, Arcangeli A, Bocci $\mathrm{MG}$, et al. A prospective, blinded evaluation of indexes proposed to predict weaning from mechanical ventilation. Intensive Care Med 2004;30(5):830-836.

29. Tobin MJ, and Jubran A. Meta-analysis under the spotlight: focused on meta-analysis of ventilator weaning. Crit Care Med 2008;36(1): $1-7$.

30. Hanley JA, and McNeil BJ. A method of comparing the areas under receiver operating characteristic curves derived from the same cases. Radiology 1983;148(3):839-843.

31. Sassoon CS, Mahutte CK. Airway occlusion pressure and breathing pattern as predictors of weaning outcome. Am Rev Respir Dis 1993; 148(4):860-866. 